\title{
A theoretical contribution from the perspective of innovation process in wine tourism contexts
}

\section{Bruno Sousa -bsousa@ipca.pt}

Polytechnic Institute of Cávado and Ave, Portugal and member of CiTUR (Polo Coimbra)

\begin{abstract}
The innovation process, and its application to tourism, has been gradually gaining ground in the academic community as a field of study. Similarly, in recent decades, tourism has received greater attention from researchers in various sciences, varying only by the different emphases considered: economic, social, cultural and environmental. This increased attention must be welcomed, as innovation research represents a meaningful and valuable way of understanding the economic dynamics of the tourism industry, and deeper insights will be helpful for the industry and policy makers alike. The purpose of this article is to identify literature on special interest tourism innovation, in particular from the perspective of winetourism. In order to structure the sometimes unclear use of the innovation process (in tourism research), the article will present closely to primary classical innovation and entrepreneurship issues. This is a conceptual perspective that brings together the major components of innovation process and its implications in special interest tourism perspective We also consider some of the implications for management, as well as suggestions for future lines of research. This article concludes by drawing attention to the challenging research needs.
\end{abstract}

\section{Keywords:}

Consumer Behaviour, Innovation, Process Creation, Special Interest Tourism

\section{INTRODUCTION}

Over history, tourism has been a phenomenon characterized by vast innovativeness. Scientific studies have drawn attention to particularly distinctive individuals and enterprises, and their achievements have been analysed and assessed from all perspectives. No matter how spectacular and influential these innovations, and numerous others like them, they have seldom been taken on board in traditional academic innovation research as built up in the wake of Joseph 
Schumpeter (1934) (Hjalager, 2010). According to Ma and Tan (2006, p.705), "there has been an increasingly popular trend of cross-fertilization among strategic management research and entrepreneurship research, two fields deeply concerned with wealth creation and heavily influenced by Schumpeter's seminal work on innovation and creative destruction". In this context, and according Hjalager (2010), the emerging service economy in general, and the upcoming software boom of the 1980s in particular, changed the notion of innovation to include immaterial products, with the result that service industries were also gradually recognised for their measurable innovative potential (Miles, 2003). The innovation process, and its application to tourism, has been gradually gaining ground in the academic community as a field of study. Similarly, in recent decades, tourism has received greater attention from researchers in various sciences, varying only by the different emphases considered: economic, social, cultural and environmental. Fortunately, and according to Hjalager (2010), growing numbers of tourism researchers are addressing the wide palette of issues that fall within the innovation headline and expanding the methodological scope. In particular, tourism consumption patterns and the growth of "special interest tourism" (SIT) are thought to reflect the continuously increasing diversity of leisure interests of the late-modern leisure society. Tourists are looking for emotional stimuli, they want to buy feelings and not products (Douglas \& Derret, 2001; Opaschowski, 2001; Traver, 2006). According to the World Tourism Organization, tourism consumption patterns reflect the increasing diversity of interests of the late-modern leisure society with "SIT" having emerged, reflecting the new values which include "increased importance of outdoor activities, awareness of ecological problems, educational advances, aesthetic judgement and improvement of self and society"' (Traver, 2006, p. 184). This increased attention must be welcomed, as innovation research represents a meaningful and valuable way of understanding the economic dynamics of the tourism industry, and deeper insights will be helpful for the industry and policy makers alike. The purpose of this article is to identify literature on special interest tourism innovation, in particular from the perspective of wine tourism. In order to structure the sometimes unclear use of the innovation process (in tourism research), the article will present closely to primary classical innovation and entrepreneurship issues. Further sections of the article will look at the special interest tourism perspective including several examples from the perspective of sustainability 
and ecotourism management. This is a conceptual perspective that brings together the major components of innovation process and its implications in special interest tourism perspective We also consider some of the implications for management, as well as suggestions for future lines of research. This article concludes by drawing attention to the challenging research needs.

\section{INNOVATION PROCESS AND ENTREPRENEURIAL INTENTIONS}

Innovation can be seen as a specific tool of entrepreneurs, the means with which exploit change as an opportunity for a different business or service, being able to be understood and, as such, to be practiced, leading to a common distinction between invention and innovation (Drucker, 1993). Almost all the innovations reflect existing knowledge, combined with new uses, suffering the concept of innovation as a shift towards emphasis on the interaction between institutions, focus on interactive for the creation, dissemination and sharing of knowledge and relevance of the role of government processes as an important actor in an innovative environment.

It is important to clarify the difference between two concepts that, for different times, tend to be confused: Process Innovation and the Innovation Process. Innovation Process is essentially related to the set of steps that tend to incorporate both the market and technology. Companies have the ability to go seizing, building your knowledge base and thus make the continuous improvement of process management (Tidd, Bessant \& Pavitt, 2003). Monitor the internal and external environment and analyze the relevant signals will be the starting point. After this, we have the decision about how to respond. Finally, we will implement the project with the development of technology and the domestic and foreign market.

The Process Innovation, by the way, combines the adoption of a process view of the organization's business with the application of innovation to key processes (Sousa, 2015). This is the big difference, compared with the Innovation Process, but it allows us to understand its complexity. Process Innovation encompasses the prediction of new work strategies, the actual process activity and the implementation of change in their complex human, technological and organizational dimensions (Davenport, 1993).

Product or service innovations refer to changes directly observed by the customer and regarded as new; either in the sense of never seen before, or new to 
the particular enterprise or destination. Product or service innovations are perceptible to tourists to such an extent that they may well become a factor in the purchase decision (Hjalager, 2010). According to Hjalager (2010; Process innovations refer typically to backstage initiatives which aim at escalating efficiency, productivity and flow. Technology investments are the anchor of mainstream process innovation, sometimes in combination with reengineered layouts for manual work operations. Information and Communication Technology (ICT) has been the backbone of many process innovations in recent decades, and it has attracted a significant strand of research interest with its own agendas and institutions (Buhalis \& Law, 2008). Some research contributions dig into the stages of technology utilization and the gradual evolvement and deepening of the process innovations.

According to Davenport (1993), in practice, companies need to combine the two concepts in a continuous quality program. Ideally, the organization will seek to stabilize the process and start continuous improvement, to later create the ambition to go on the innovation processes. The differences between these two concepts can hinder your combination, so one of the possibilities to minimize this problem may be the assignment of different roles to different managers, with high levels of cooperation. The company must be aware that the risk of innovation processes is at least proportional to the rewards for that in reduced competitiveness continuous improvements environments may be the preferred choice. Highly competitive environments (e.g. greater balance between enterprises, reduced rate of market growth, high barriers to exit) may encourage the bet on a change with the greatest impact (process innovation). Access to information and the challenge of the information revolution is also the base of the reach of competitive advantage, in order to maximize innovation in the process and, consequently, greater differentiation from competitors (Porter \& Millar, 1985).

In this context, entrepreneurial activity is seen as a process: includes a set of steps, is subject to management, continuous and applicable in many contexts (Stevenson \& Jarillo, 2007). This process becomes a source of competitive advantage on a global scale. This entrepreneurial process is, as a rule, inextricably linked to certain factors that allow initial "take the leap" (circumstances, triggering events). Shindehutte et al. (2000) present a conceptual model (figure 1) that summarizes the dynamic nature of the triggering process in an attempt to summarize the various 
contributions on this topic. The entrepreneurial process is conceptualized as a response to the awakening of the event. However, the nature of the trigger, relevance and impact depends on the dynamic interaction between the characteristics of managers / employees (e.g., personal life), firm characteristics (e.g., size, culture) and external developments of the environment (e.g., competitiveness). The different types of entrepreneurial activities are probably the result of different types of triggers.

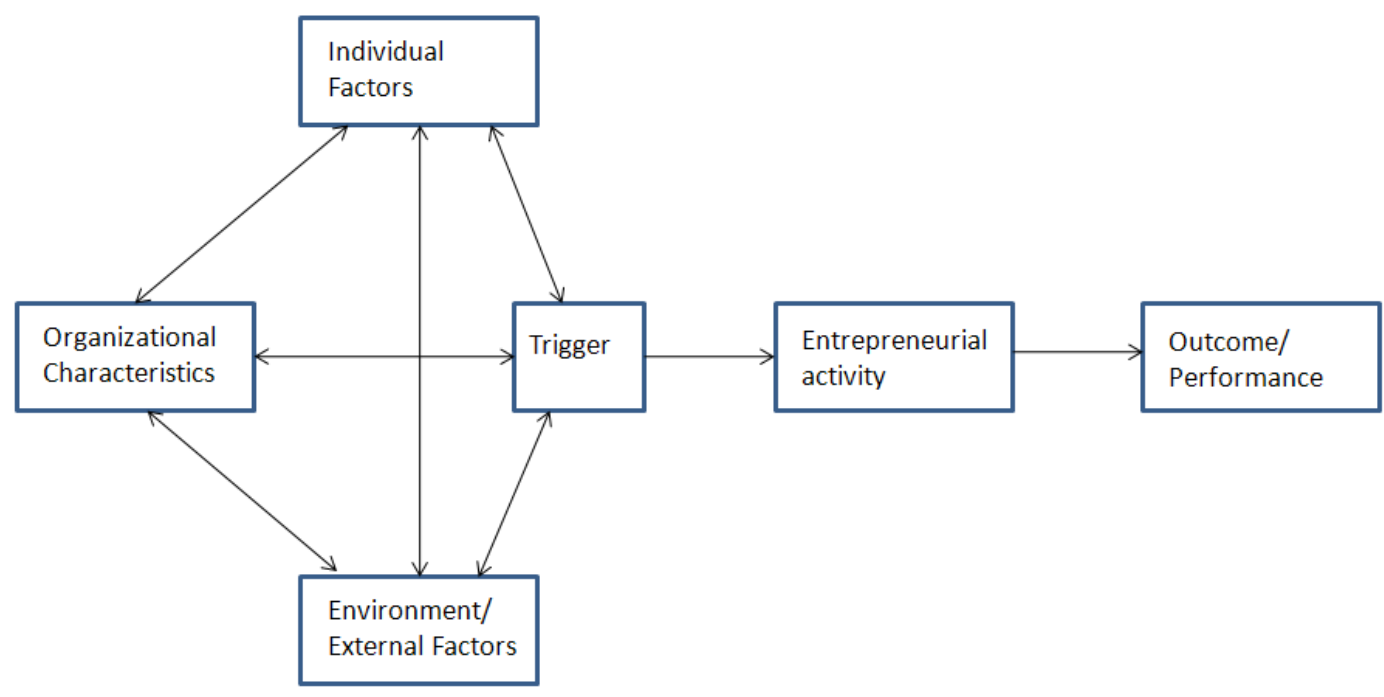

Figure 1: Dynamic Triggering Process Model

Source: Shindehutte et al. (2000)

Therefore, and according to Stamboulis and Skayannis (2003), being part of the service sector, tourism has inevitably been associated with developments in new technologies and refreshed by organizational and structural innovations. There has been a trend to flexibilization of the tourist product by a form of customization, despite the pressure from tourist operators who still advocate packages of mass tourism. The trends towards 'advanced' facets of the service 'post-industrial' (information) society-customization, flexibilization-render knowledge the new decisive competitiveness factor. Inescapably, this leads to the consideration of learning as a dynamic capability. In the competitive landscape of tourism, any location or business aiming to do better than others, should become either a learning 
region or a learning industry. Even more, "emerging alternative tourism has to engage the element of culture, which gains in importance and has to be continuously transformed" (Stamboulis and Skayannis, 2003, p.35).

The tourism industry is undergoing significant restructuring. According to Stamboulis and Skayannis (2003, p.35), "the combination of mass and conventional tourism has so far formed the major part of the organized tourist business, with non-mass alternative tourism having the smaller part of the pie. Mass tourism may, under certain conditions, be alternative, as conventional tourism may be non-mass or individualized". The term 'conventional' refers to the type of activities the tourists follow (for instance the '4Ss', i.e. sea, sun, sand, sex), while the term 'mass' predominantly refers to numbers of tourists. We will dedicate a subpoint to the study of special interest tourism in this article in the next section or our research.

According to Ottenbacher and Harrington (2008), there are a number of models of the innovation process. Most are based on new product development (NPD) models derived from an engineering perspective, and consist of six main steps: (1) idea generation, (2) screening, (3) business analysis, (4) concept development, (5) final testing and (6) commercialisation (e.g. Booz et al, 1982). Although the use of a development model in the innovation process does not guarantee success, research has demonstrated a connection between the use of innovation process models and an increase in the likelihood of success in a variety of settings (Ottenbacher et al, 2006). For instance, Ottenbacher and Harrington (2007) looked at the new innovation development process used by Michelin-starred chefs in Germany. Research results indicated that the development process in this setting had similarities to and differences from traditional concepts of NPD.According to Hjalager (2010), process innovations may be platforms for improved services that will be recognizable to the customer and add to the value of the product. For example automatic check-in-systems can save time for both customers and staff. According to Hjalager (2010), empirical studies, however, tend to conclude that the lodging industry employs technology to improve employee productivity and enhance revenues, but that limited strategic priority is given to technologies designed to improve guest services (Martin, 2004; Siguaw, Enz, \& Namasivayam, 2000; Sundbo et al., 2007). Svejenova et al (2007) evaluated the change process in a high-end culinary setting. 
Specifically, the research team considered Ferran Adrià's professional evolution as a leader in the field, as well as creating a theoretical model (based on earlier models of creativity (e.g. Drazin et al, 1999)) on how institutional entrepreneurs initiate change (figure 2).

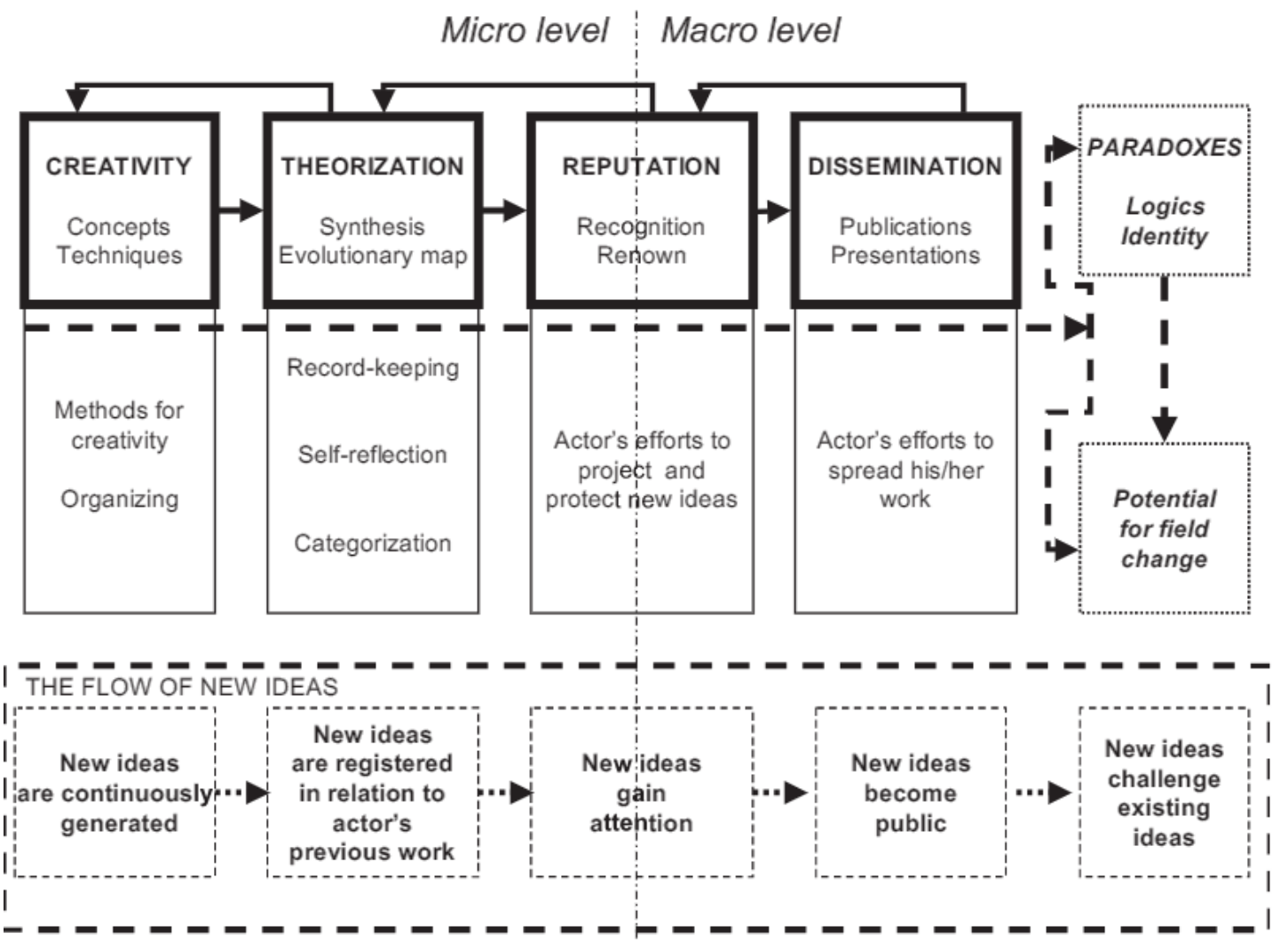

Figure 2: How an institutional entrepreneur initiates change Source: Svejenova et al (2007)

In conclusion, and according to Stamboulis and Skayannis (2003), tourism is undergoing significant change and facing new challenges. At least two dimensions of the change can be identified: new forms of tourism, characterized by the tendency to depart from mass tourism and the diffusion of information and communication technologies, with a pervasive effect on the creation, production and consumption of the tourist product. Consumer behaviour in tourism consumption has been changing, developing a more segmented, specialised and sophisticated market mainly aiming at unique activities available at the places visited (Nylander \& Hall, 2005; Robinson \& Novelli, 2005; Novelli, Schmitz \& Spencer, 2006).

According to Aldebert, Dang \& Longhi (2011), tourism encompasses all the 
activities dedicated to the satisfaction of tourists' needs, and borrows from multiple activities. Products addressed to tourists are complex and heterogeneous; they constitute a combination of elements separated in time and space (Caccomo \& Solonandrasana, 2001), and often are packages of interrelated products and services (transport, accommodation services, leisure services. This notion of packaging and bundling is the core of the tourism industry activity (Aldebert, Dang \& Longhi, 2011). Innovative attempts gain new strategic value when viewed from a perspective that values experience as an important new attribute, in specific the case of "special interest tourism" (SIT).

\section{SPECIAL INTEREST TOURISM (SIT)}

It is acknowledged that it is difficult, if not even impossible, to define tourism, or Special Interest Tourism (SIT), in a manner acceptable to researchers across the spectrum of tourism disciplines and research approaches (Butler, 1999; Traver, 2006). According to Traver (2006), Brotherton and Himmetoglu (1997) in their attempt to conceptualize and define SIT, reviewed literature within leisure and tourism, comparing existing typologies and frameworks (leisure and tourism contexts). According to Wearing (2002), the tourist in the 21 st century is 'searching for new and exciting forms of travel in defiance of a mass-produced product yet without 'actually having to involve themselves in any way', a reflection of increasing commodification and depersonalization within modern and post-modern society (Traver, 2006). Visitors want to personally experience the immaterial qualities, seeking ambiance, aesthetics and atmosphere, looking for an experience full of varying intimacies, intensities and complexities (Traver, 2006). Process innovations, take place widely in special interest tourism and niche tourism perspective. For instance, from winter sports, Clydesdale (2007) explains how ski lift capacity is a critical element in process efficiency and that choice of technology for that purpose is decisive. Airports adopt a wide variety of technologies that ensure the mobility of people, luggage, goods and information, in order to alleviate the challenges of transportation (Hjalager, 2010). Over the years, and for a number of reasons, new types of technology have entered airports. The same style of process innovation can be found permeating into visitor attractions for 
the purposes of crowd control. Process innovations that address energy consumption and climate impacts are on the future agenda for many types of tourism enterprise, not least transportation (Peeters, Gossling, \& Becken, 2006; Hjalager, 2010).

Tourism is a phenomenon that moves millions of people around the world, taking as a major driver of the global economy. Every year, much due to the frequent changes in the tourism environment, fosters competition between and within tourist destinations (Bigné \& Andreu, 2004). It is multifaceted and geographically complex activity, where different services are ordered and delivered in different stages, from origin to destination (Pearce, 1991). To set Special Interest Tourism (SIT) in a broader overall tourism context, Brotherton and Himmetoglu (1997) suggest a "Tourism Interest Continuum". Based on Culligan's framework, they propose that "through increasing travel experience, confidence and affluence, a maturation or tourist life cycle transition from "safe to more adventurous kinds of travel and holidays" occurs, with the tourist "trading up" and purchasing social prestige and ego-enhancement" (Traver, 2006, p. 187). As a psychological phenomenon, a tourist trip is preceded by a specific need that generates a reason to travel and sets a goal for the trip, which follows the search for information (Gursoy \& McCleary, 2004). Like other emerging sectors in a modern economy, tourism is a dynamic and ever-changing industry.

Consequently, Special Interest Tourism (SIT), both as a product or sector in its own right and as a distinct entity within the overall tourism spectrum, has been largely ignored as an important area of study within the tourism field in general. Trends in global tourism demand suggest the emergence of sophisticated consumers looking for new, different and specific tourist experiences. In such context, niche marketing seems a relevant response to market dynamics. Although niche marketing has been successfully applied to a high number and many types of businesses, there is a shortage of research addressing the way niche marketing may be applied to tourism (Dalgic \& Leeuw, 1994; Sousa \& Simões, 2010).

Therefore, and according to Robinson and Novelli (2005), the term 'niche tourism' is largely borrowed from the term 'niche marketing', which in turn has appropriated the niche concept from the language of the relatively recent discipline of ecology. Hutchinson (1957) is widely credited with introducing the concept of 'niche' referring, in its widest sense, to a region in a multidimensional space 
characterised by environmental factors that affect the welfare of the species. At one end of the spectrum then "niche tourism can be defined as breaking down into still relatively large market sectors (macro-niches - i.e. cultural tourism, rural tourism, sport tourism, etc.), each capable of further segmentation (micro-niches - i.e. geo-tourism, gastronomy tourism, cycling tourism, etc.). At the other end of the spectrum, niche tourism is focused on very precise small markets that would be difficult to split further" (Robinson \& Novelli, 2005, p.6).According Robinson \& Novelli (2005), we can consider several cases of niche tourism address a wide variety of motivations, behaviours and experiences from both the perspective of production and consumption. They provide an integrated picture of niche tourism as a whole, looking at specific scenarios, offering a comprehensive theoretical framework and discussing initiatives, policies and strategies adopted internationally.

\section{WINE TOURISM: PRODUCTS AND SERVICES INNOVATION}

Sustainable tourism development should be seen as an adaptive paradigm, a part of the parental concepts of development and sustainable development, and it should aim at contributing to objectives of sustainable development and development in general by determining specific principles in the light of its parental concepts (Tosun, 2001), for instance wine tourism contexts. According to Hassan (2000), tourism marketing for the new millennium and beyond must focus on forms of tourism that are sensitive to promoting and sustaining the environmental integrity of natural and cultural heritage resources. Negative effects of tourism development and growth on the destination and its environment can decrease its long term comparative advantage and reduce tourist demand.

The definition and conceptualization of "wine tourism", according to Getz and Brown (2006) has not resulted in a uniform approach. When viewed from a marketing perspective emphasis is likely to be placed on determination of the experiences sought by potential and actual wine tourists. In fact, most definitions of wine tourism do relate to the traveler's motivation and experiences. Thus, "wine tourism" is, simultaneously a form of consumer behavior, a strategy by which destinations develop and market wine-related attractions and imagery, and a marketing 
opportunity for wineries to educate, and to sell their products, directly to consumers (Getz \& Brown, 2006).

According to Bruwer and Alant (2009), the wine tourist is a person with needs to relate to both wine and the location (wine region) where wine is produced. In a broader context wine tourism may be linked to other lifestyle activities and to travel per se. The really question "who is the wine tourist?" has yet to be answered. In this context, the innovative attempts gain new strategic value when viewed from a perspective that values experience as an important new attribute, in specific the case of wine tourism (products, services, ideas, experiences).For instance, the Monverde Wine Experience Hotel is located in Amarante (Portugal), covering an estate of 30 hectares, of which 22 are dedicated to the production of grapes for Quinta da Lixa's green and sparkling wines, this pioneering regional wine hotel has added a passion for wine tourism and ecotourism. The architects, FCC Arquitetura, have preserved the building's heritage, cultural inheritance and the value given to nature. The surroundings, the climate and even the traditions provoke, define and promote the interior design". At Monverde, "the essence, the tranquillity, inspires us to live, contemplate and value what is around us" (figure 3).

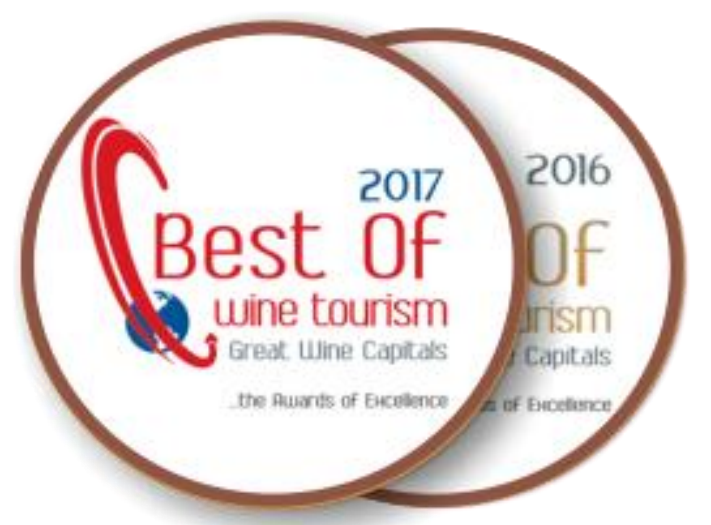

Figure 3 - Best of wine tourism - innovation services

The Great Wine Capitals Best Of Wine Tourism Awards celebrate innovation and excellence in wine tourism throughout the nine greatest wine regions in the world. The Best Of program provides an opportunity for wineries and other visitor-serving businesses in each region to gain exposure and recognition for their commitment to presenting leading wine tourism options while giving visitors a one-stop list of the best 
places to experience.This International competition is designed to reward businesses in each member region that have distinguished themselves in terms of the excellence of their facilities and delivering quality experiences to visitors in various categories. Awards are given in the following seven categories: accommodation, wine tourism restaurants, sustainable wine tourism practices, architecture \& landscape art \& culture, innovative wine tourism experiences, wine tourism services.

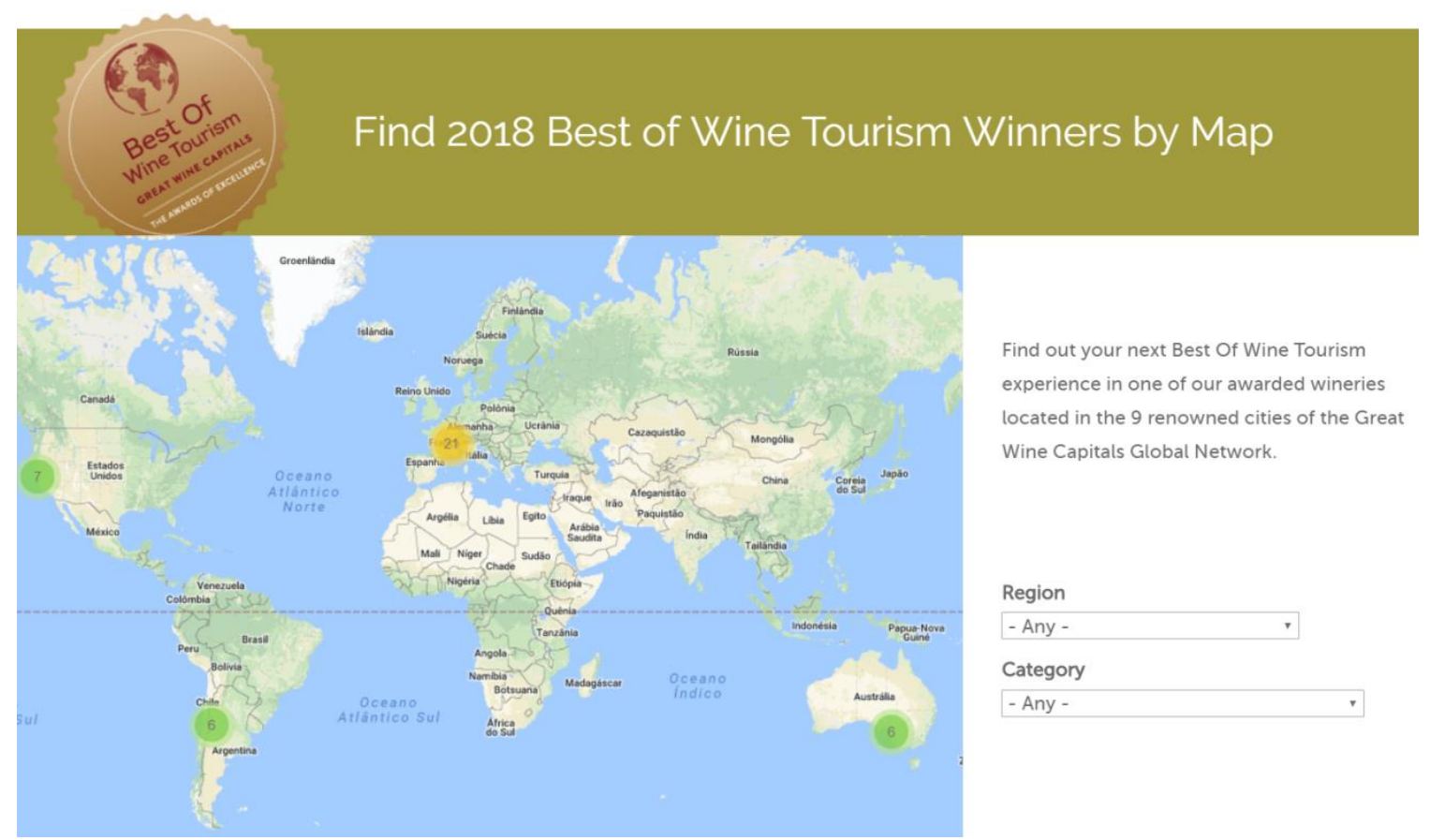

Figure 4 - Best of wine tourism winners by map - innovation digital process

Another example of innovation and creativity in wine services (and consequently wine tourism services and products) is Vivino app. Vivino is the world's most popular wine community and most downloaded mobile wine app. Vivino's 26 million users contribute ratings for millions of wines from around the globe, and collectively, this database makes up the largest wine library in the world. Vivino is changing the way people wine (figure 5). 


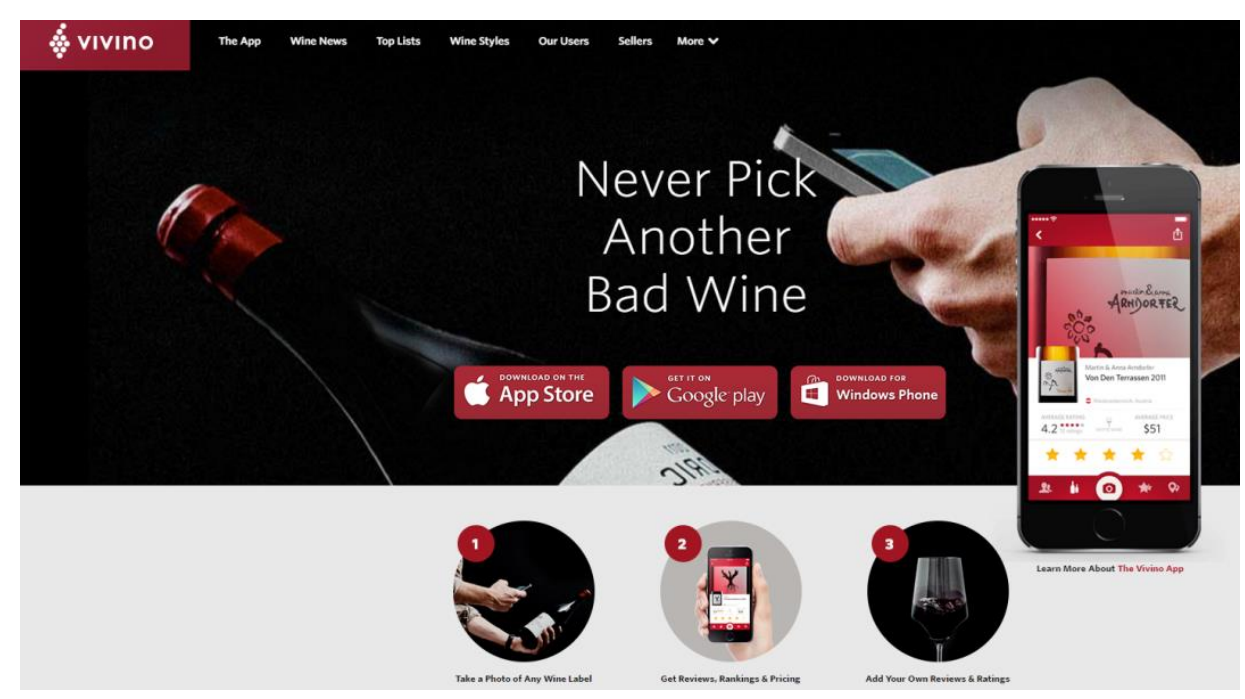

Figure 5 - Vivino app - innovation app (products and services)

Also Vinitur is a practical example of service innovation. VINITUR is a complete Destination Management Company providing fine customized programs around wine, food \&culture. This service has dedicated to special groups, corporate clients and gourmet \& luxury journeys for leisure travelers. Their innovative approach include wine, food and culinary itineraries, touristic experiences, gourmet experiences, incentives, meetings and conferences. Other portuguese example is Omdesign. Four awards is the balance of Omdesign's participation in this year's Creativity International Awards. The Portuguese agency was distinguished with Gold by the packaging developed for the Vintage Murganheira - Mestre Júlio Resende special edition.In the luggage there is also space for two Silver and one Bronze awards. The Silvers arrive through the books "Martins da Costa - Contos Vividos", created for the Penacova City Hall, and "300 Years in the heart of the Douro", developed for Quinta do Vallado. The Bronze, in turn, was awarded to the "Omdesign 2016" self-promotion package. With the new achievements, Omdesign has already added 44 distinctions since the beginning of the year. The portuguese agency has been recognized by national and international design competitions (figure 6). 


\section{om design}
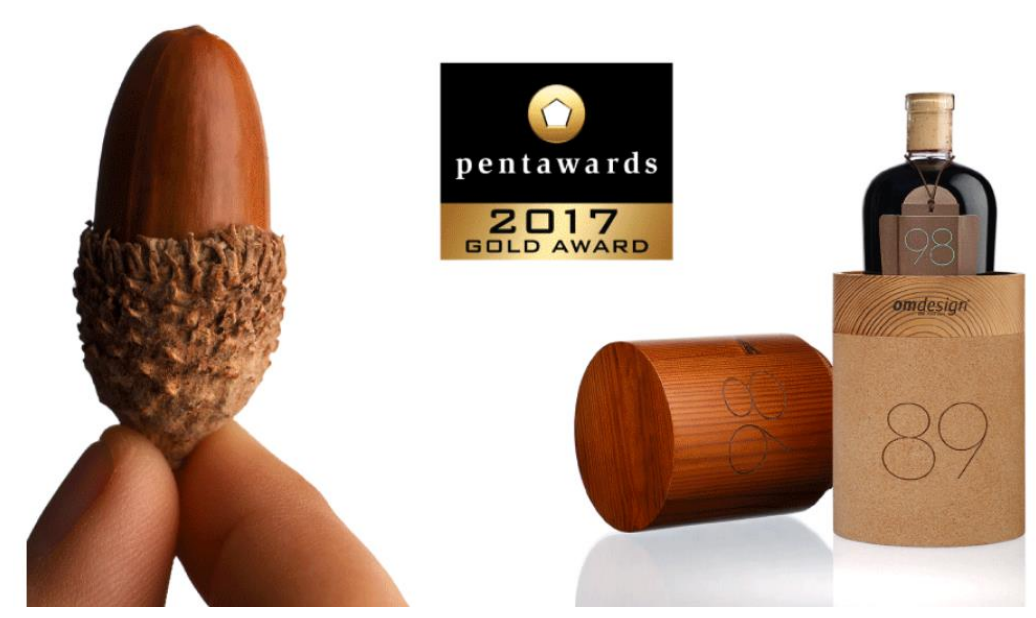

Figure 6 - Omdesign pentawards 2017 - innovation design

\section{CONCLUSIONS, LIMITATIONS AND NEXT STEPS}

In an increasingly global world, which tends to predominate competitiveness and change, the difference is, often, the ability to create discontinuities in the external environment. Many times the success is the ultimate goal, which focuses on searching for new products, new markets, new organizational forms and new sources of customer value. The purpose of this article was to identify contributes on special interest tourism innovation, in particular from the perspective of wine tourism, and products and services in wine management. In order to structure the sometimes unclear use of the innovation process (in tourism research), the article presented to primary classical innovation and entrepreneurship issues. For instance, the creation process associated with for nature and sustainable reservation systems, mechanisms and information sharing as a form of competitive advantage over other tourist destinations (social networks), the marketing of nature and sustainable, nature and wine tourism (products and services) as well as other related activities that can leverage the increased business synergies.

It is expected that future work can contribute to the development of empirical studies to test the relationships in process innovation and wine tourism contexts. 
Overall the idea would be to measure the constructs and to gauge the impact of certain factors in the predisposition to process innovation into visitors and entrepreneurs and focus group in special interest tourism contexts. Thus, an empirical study will not only test the propositions but also bring a quantitative and qualitative perspective. The generators entrepreneurship and innovative factors that may trigger an entrepreneurial activity and whose origin may be associated with internal, external factors and characteristics of the organization. This study is primarily theoretical and reflection, thereby is expected to arise in the future some work of a practical nature that bring greater robustness to support and perspectives presented.

\section{ACKNOWLEDGEMENTS}

UNIAG, unidade de I\&D financiada pela FCT - Fundação para a ciência e a Tecnologia, Ministério da Ciência, Tecnologia e Ensino Superior, no âmbito do projeto "UID/GES/4752/2016".

\section{REFERENCES}

Aldebert, B., Dang, R. J., \& Longhi, C. (2011). Innovation in the tourism industry: The case of Tourism@. Tourism management, 32(5), 1204-1213.

Bigne, J. E., \& Andreu, L. (2004). Emotions in segmentation: An empirical study. Annals of Tourism Research, 31 (3), 682-696.

Booz, \& Allen \& Hamilton. (1982). New products management for the 1980s.Booz, Allen \& Hamilton.

Brotherton, B., \& Himmetoglu, B. (1997).Beyond destinations-special interest tourism. Anatolia, 8(3), 11-30.

Bruwer, J., \& Alant, K. (2009). The hedonic nature of wine tourism consumption: an experiential view. International Journal of Wine Business Research, 21 (3), 235-257.

Buhalis, D., \& Law, R. (2008). Progress in information technology and tourism management: 20 years on and 10 years after the Internet - The state of eTourism research. Tourism management, 29(4), 609-623.

Butler, R. W. (1999). Sustainable tourism: A state-of-the-art review. Tourism geographies, 1(1), 7-25.

Clydesdale, G. (2007). Cultural evolution and economic growth: New Zealand Maori. Entrepreneurship and Regional Development, 19(1), 49-68.

Dalgic, T., \& Leeuw, M. (1994). Niche marketing revisited: concept, applications and some European cases. European Journal of Marketing, 28(4), 39-55. 
Davenport, T. H. (1993). Process innovation: reengineering work through information technology. Harvard Business Press.

Douglas, N., \& Derrett, R. (2001). Special interest tourism.John Wiley and Sons Australia, Ltd.

Drucker, P. F. (1993). Managing for the Future.Routledge.

Getz, D., \& Brown, G. (2006). Critical success factors for wine tourism regions: a demand analysis. Tourism management, 27(1), 146-158.

Gursoy, D., \& McCleary, K. W. (2004).An integrative model of tourists' information search behavior. Annals of tourism research, 31 (2), 353-373.

Hardy, A., Beeton, R. J., \& Pearson, L. (2002). Sustainable tourism: An overview of the concept and its position in relation to conceptualisations of tourism. Journal of Sustainable Tourism, 10(6), 475-496.

Hassan, S. S. (2000). Determinants of market competitiveness in an environmentally sustainable tourism industry. Journal of travel research, 38(3), 239-245.

Hjalager, A. M. (2010). A review of innovation research in tourism. Tourism management, 31 (1), 1-12.

Iso-Ahola, S. E. (1983). Towards a social psychology of recreational travel. Leisure Studies, 2(1), 45-56.

Ma, H., \& Tan, J. (2006). Key components and implications of entrepreneurship: A 4-P framework. Journal of Business Venturing, 21 (5), 704-725.

Martin, L. M. (2004). E-innovation: internet impacts on small UK hospitality firms. International Journal of Contemporary Hospitality Management, 16(2), 82-90.

Miles, I. (2003). Services and the knowledge-based economy. Service innovation, organizational responses to technological opportunities \& market imperatives. London, 81-112.

Novelli, M., Schmitz, B., \& Spencer, T. (2006). Networks, clusters and innovation in tourism: A UK experience. Tourism management, 27(6), 1141-1152.

Nylander, M., \& Hall, D. (2005). Rural tourism policy: European perspectives. Rural tourism and sustainable business, 17-40.

Opaschowski, H. W. (2001). Das gekaufte Paradies-Tourismus im 21. Jahrhundert. Hamburg.

Ottenbacher, M., \& Harrington, R. J. (2008). The culinary innovation process: A study of Michelin-starred chefs. Journal of Culinary Science \& Technology, 5(4), 9-35. 
Ottenbacher, M., \& Harrington, R. J. (2007).The innovation development process of Michelin-starred chefs. International Journal of Contemporary Hospitality Management, 19(6), 444-460.

Peeters, P., Gossling, S., \& Becken, S. (2006). Innovation towards tourism sustainability: climate change and aviation. International journal of innovation and sustainable development, 1 (3), 184-200.

Porter, M. E., \& Millar, V. E. (1985). How information gives you competitive advantage.

Robinson, M., \& Novelli, M. (2005). Niche tourism: an introduction. Niche tourism: Contemporary issues, trends and cases, 1-11.

Schindehutte, M., Morris, M. H., \& Kuratko, D. F. (2000). Triggering events, corporate entrepreneurship and the marketing function. Journal of Marketing Theory and Practice, 8(2), 18-30.

Schumpeter, J. (1934). Capitalism, socialism, and democracy.

Siguaw, J. A., Enz, C. A., \& Namasivayam, K. (2000). Adoption of information technology in U.S. hotels: strategically driven objectives. Journal of Travel Research, $39,192-201$.

Sousa, B. (2015). Dynamic differentiation and the creative process in tourism management destinations, Revista Brasileira de Pesquisa em Turismo - RBTur, 10(1), pp. 3-17, jan./abr. 2015, São Paulo, e-ISSN 1982-6125.

Sousa, B., \& Simões, C. (2010). Comportamento e perfil do consumidor de turismo de nichos. Tékhne-Revista de Estudos Politécnicos, (14), 137-146, ISSN: 1645-9911.

Stankey, G. H. (1973). Visitor perception of wilderness recreation carrying capacity.

Stevenson, H. H., \& Jarillo, J. C. (2007). A paradigm of entrepreneurship: Entrepreneurial management. Entrepreneurship: Concepts, theory and perspective, 155-170.

Stamboulis, Y., \& Skayannis, P. (2003).Innovation strategies and technology for experience-based tourism. Tourism management, 24 (1), 35-43.

Sundbo, J., Orfila-Sintes, F., \& Sørensen, F. (2007).The innovative behaviour of tourism firms-Comparative studies of Denmark and Spain. Research policy, 36(1), 88-106.

Svejenova, S., Mazza, C., \& Planellas, M. (2007).Cooking up change in haute cuisine: Ferran Adrià as an institutional entrepreneur. Journal of Organizational Behavior, 28(5), 539-561.

Tidd, J., Bessant, J., Pavitt, K., \& Tavares, C. (2003). Gestão da inovacão: integração das mudanças tecnológicas, de mercado e organizacionais.

Tosun, C. (2001). Challenges of sustainable tourism development in the developing 
world: the case of Turkey. Tourism management, 22(3), 289-303.

Traver, B. (2006). Conceptualizing special interest tourism-frameworks for analysis. Tourism Management, 27 (2), 183-200.

Wearing, S. (2002).Re-centring the self in volunteer tourism. In G. M. S. Dann (Ed.), The tourist as a metaphor of the social world (pp. 237-262). Wallingford, Oxon: CABI Publishing. 